\title{
1 Impact of the pear psyllid Cacopsylla pyri host instar on the behavior and fitness
}

\section{2 of the parasitoid Trechnites insidious}

4 Guillaume Jean Le Goff ${ }^{1 *}$, Jeremy Berthe ${ }^{1}$, Kévin Tougeron ${ }^{1}$, Benoit Dochy ${ }^{1}$, Olivier Lebbe ${ }^{1}$,

5 François Renoz ${ }^{1} \&$ Thierry Hance ${ }^{1}$

$7 \quad{ }^{1}$ Earth and Life Institute, Biodiversity Research Centre, UCLouvain, Croix du sud 4-5 bte L7.07.04,

81348 Louvain-la-Neuve, Belgium

9

10

11 * Corresponding author: Guillaume Jean Le Goff (E-mail address: guillaume.legoff@ uclouvain.be)

12

13

14

15

16

17

18 


\section{Abstract}

24 1. Pear is one of the most important fruit crops of temperate regions. The control of its mains pest,

25 Cacopsylla pyri, is still largely based on the use of chemical pesticides, with all that this implies in

26 terms of negative effects on the environment and health.

27 2. Within the context of integrated pest management, innovative and ecologically sustainable

28 strategies must be developed for. Although Trechnites insidiosus is the most abundant parasitoid of

29 C. pyri, its biology and its potential as a control agent have been little studied.

30 3. In this paper, we conducted experiments to evaluate the behavior of the specialist parasitoid $T$.

31 insidiosus when exposed to different larval instars of the pear psyllid C. pyri, and to assess the

32 quality of the next generation of parasitoids.

33 4. We found that although T. insidiosus accepts all host instars for oviposition, the third and fourth

34 instars were the most suitable host in terms of behavioral acceptance and progeny development.

35 5. Our study is a first step for further studies on the interaction between psyllids and parasitoids and

36 provides evidence that the specialist parasitoid T. insidiosus is a promising candidate for biological

37 control strategies of the pear psyllid C. pyri.

39 Key words:, locomotor activity, host acceptance, host suitability, offspring quality, pear orchards,

40 biological control 


\section{Introduction}

47 Pear (Pyrus communis L.) is one of the major cash crops in temperate climates, with 1,381,923

48 hectares dedicated to its cultivation and approximately 24 million tons of pear produced in orchards

49 in 2018 ("FAOSTAT,” 2020). The European pear psylla Cacopsylla pyri L. (Hemiptera: Psyllidae)

50 is the most important pest of European pear trees. It infests all commercial pear tree varieties, is

51 distributed throughout the pear cultivation area, and therefore presents a serious threat to pear

52 production and causes heavy economic losses (Civolani, 2012; Dupont and Strohm, 2020). Both

53 immature and adult psyllids feed on phloem sap and cause direct damages to pear trees and yield

54 losses by subtracting nutrients and weakening the host plant. $C$. pyri also cause indirect damages by

55 spreading fungi, such as sooty molds, mostly caused by a high honeydew excretion (Civolani, 2012;

56 Sanchez and Ortin-Angulo, 2012). These pests also transmit various phytopathogens such as the

57 phytoplasma Candidatus Phytoplasma pyri (Seemüller and Schneider, 2004), which is responsible

58 of pear decline disease, reducing tree vigor (Civolani, 2012).

59 Control of $C$. pyri is currently mainly based on Integrated Pest Management (IPM), which

60 relies on a mixture of natural and chemical control strategies (Civolani, 2012). However, excessive

61 use of non-selective chemicals alone decreases the effectiveness of spray treatments over time due

62 to the development of biotic resistance in psyllid populations (Buès et al., 2003; Erler, 2004;

63 Civolani et al., 2007). With the banning of an increasing number of phytochemicals and the

64 increasing public demand for organic food production, it is important to develop new approaches

65 for the control of psyllids that are more environmentally and human health friendly. Biological

66 control and the use of beneficial insects are already used as part of IPM strategies in pear orchards.

67 For example, several bug species of the Anthocoridae family (Hemiptera) (e.g. Anthocoris

68 nemoralis) are generalist predators of the pear psylla in orchards. The natural the presence of these

69 generalist predators in pear orchards is not sufficient to regulate psyllid populations below

70 sustainable economic threshold (Booth, 1992; Erler, 2004; Civolani, 2012), but mass releases of

71 anthocorids into orchards have been shown to be effective in reducing pear psyllid populations 
72 (Sigsgaard et al., 2006a,b). However, the use of these generalist predators on a large scale faces

73 many limitations, including the high cost of mass releases, the high pesticide sensitivity of

74 anthocorids, and the lack of targeted control with a broad spectrum of insects that can be targeted by

75 these predators (Booth, 1992; Civolani, 2012; Emami et al., 2014). To overcome the weaknesses of

76 the currently used control methods, it is important to find more specific biological control strategies

77 to meet the current demand for fruit produced in a more environmentally friendly and healthy way.

The use of specialist parasitoids are promising alternatives or complements to the use of

79 generalist predators, due to their host-specificity, foraging capacity, high fecundity rate, and lack of

80 negative side-effects in the environment. The parasitofauna of $C$. pyri is quite diversified and

81 several species have been reported in pear orchards, including Trechnites insidiosus, Prionomitus

82 mitratus (Dalman), P. tiliaris (Dalma,), Endopsylla sp., Psyllaephagus procerus Marcet,

83 Syrphophagus ariantes (Walker), Syrphophagus taeniatus (Fo $\square$ rster) and Tamarixia sp (Armand et

84 al., 1990, 1991; Erler, 2004; Guerrieri and Noyes, 2009; Jerinic-Prodanovic et al., 2010). However,

85 no attempts have been reported to rear these species for mass production, and little information is

86 available on their biology, general ecology, and potential effects in a biological control context

87 (Tougeron et al., 2021). Of these parasitoids, $T$. insidiosus is consistently cited as the most abundant

88 species in the pear orchards (Armand et al., 1991, 1990; Avilla and Artigues, 1992; Booth, 1992;

89 Bufaur et al., 2010; Erler, 2004; Herard, 1985; Miliczky and Horton, 2005; Sanchez and Ortin-

90 Angulo, 2012), even though it exhibits significant susceptibility to chemical treatments (Burts,

91 1983; Lacey et al., 2005; Sanchez and Ortin-Angulo, 2012) and relatively high levels of

92 hyperparasitism (McMullen, 1966; Armand et al., 1991, 1990; Sanchez and Ortin-Angulo, 2012). It

93 is a koinobiont parasitoid that has interesting attributes for IPM of pear psyllids. First, it has a wide

94 activity window, from early April to late November, which means it can be active at fairly low

95 temperatures (Armand et al., 1991, 1990; Bufaur et al., 2010; Dupont and Strohm, 2020; Herard,

96 1985; Oudeh et al., 2013). T. insidiosus also has a first generation free of hyperparasitism (Armand

97 et al., 1991, 1990). This parasitoid is therefore capable of significant and early activity at the first 
98 generation of pear psyllids, before the arrival of massive predators. T. insidiosus has been purposely

99 introduced in California as a biological control agent to limit populations of introduced psyllid pests

100 (Retan and Peterson, 1982; Unruh et al., 1995; Guerrieri and Noyes, 2009), but little information is

101 available on its establishment success and effectiveness in controlling psyllids. The few field studies

102 have revealed peak parasitism levels that vary between 30 to $100 \%$ depending on location (Bufaur

103 et al., 2010; Erler, 2004; Jaworska et al., 1998; Oudeh et al., 2013), suggesting effective control of

104 psyllid populations by T. insidiosus (Talitski, 1996 in Unruh et al., 1994).

105 To date, no experimental studies have been conducted to identify the parasitic behavior of $T$.

106 insidiosus towards the pear psyllid Cacopsilla pyri. In this study, we conducted experiments to 107 determine the set of behaviors that female $T$. insidiosus exhibit towards $C$. pyri as well as the 108 physiological responses of T. insidiosus as a function of host developmental instar. The quality of

109 the next generation parasitoids was assessed by measuring their developmental time, fecundity,

110 size, and sex ratio, which are commonly used as proxies for assessing parasitoid fitness (Colinet et 111 al., 2005). Previous studies have reported T. insidiosus females to preferentially lay eggs in the 112 fourth and fifth larval instars of pear psyllids (Armand et al., 1991, 1990; Booth, 1992), while 113 others have reported that they primarily oviposit in the first and second larval instars of psyllids 114 (McMullen, 1966). Our study assumes that T. insidiosus females are capable of ovipositing in all 115 larval development instars of $C$. pyri, with a preference for the more mature instars that would be 116 more suitable hosts from a nutritional standpoint. We also hypothesized that parasitoids emerging 117 from the older developmental instars exhibit better fitness indicators than individuals developing in 118 younger instars of the psyllid.

\section{Material and methods}

\section{Biological models}

122 The insects used for the experiments were initially collected from populations sampled in 2013 for 123 Cacopsylla pyri and in 2016 for Trechnites insidiosus in the experimental pear orchard of 
124 Proefcentrum voor Fruitteelt, Sint-Truiden-Belgium. Populations were maintained in the laboratory

125 on pear trees in standardized sequential rearing conditions, that allowed to control the instar and the

126 age of the insects, under the following conditions: $24^{\circ} \mathrm{C}, 60 \%$ relative humidity, and $18: 8 \mathrm{~h}$

127 photoperiod (Light:Dark).

128 The influence of host development on parasitoid behavior

129 Groups of twenty psyllid larvae of the same developmental instar (first-, second-, third-, fourth-,

130 and fifth-instar larvae) were placed on artificial diet feeders and were let settling for two hours.

131 Artificial feeder setups consisted of $500 \mu \mathrm{L}$ of a nutritive solution (supplied by Viridaxis SA,

132 Belgium) placed on top of a $5.5 \mathrm{~cm}$ diameter Petri dish and spread with a piece of parafilm $5 \mathrm{~cm}$

133 square and stretched over the dish. The use of an artificial diet in the experiment allows to

134 standardize the environment and avoids a potential influence of the host plant on the behavior of the

135 parasitoids. The differentiation of larval instars was based on morphological criteria: the first three

136 larval instars are creamy-yellow colored, while the fourth and the fifth instars vary between

137 greenish-brown to dark-brown (Chang, 1977). The first instar larva is the same size as psyllid eggs,

138 the second instar larva is twice as large, and the third instar larva has wing pads, which gradually

139 grow in the fourth and fifth larval instars (Chang, 1977). A mated T. insidiosus female aged of less

140 than 48 hours was then placed at the center of the set up and its behavior was recorded for thirty

141 minutes with a Sony handycam (HDR XR200VE), during the afternoon. Ten replicates par larval

142 instar were performed, using a naïve parasitoid female for each replicate. Using the event recorder

143 software ODRec 3.0 (@ Samuel Péan), we recorded and quantified: 1) the number of host-feeding

144 behavior (when the parasitoid actively feeds on the host), 2) the time spent feeding on the host

145 (expressed as a percentage of the total experimental time), 3) the time spent grooming (expressed as

146 a percentage of the total experimental time), 4) the time spent walking (expressed as a percentage of

147 the total experimental time), 5) the time spent resting (expressed as a percentage of the total

148 experimental time), 6) the number of antennal contacts with the psyllid, and 8) the number of

149 ovipositor insertions into the host (Albitar et al., 2016; Augustin et al., 2020). The host acceptance 
bioRxiv preprint doi: https://doi.org/10.1101/2020.11.09.374504; this version posted April 16, 2021. The copyright holder for this preprint (which

was not certified by peer review) is the author/funder, who has granted bioRxiv a license to display the preprint in perpetuity. It is made available under aCC-BY 4.0 International license.

150 rate was calculated as the number of ovipositor insertions divided by the number of antennal

151 contacts.

\section{The influence of host development on parasitism and offspring quality}

153 After the behavioral bioassays, all psyllid larvae from a same replicate were placed on a same pear

154 tree for fourteen days to await the formation of mummies (i.e., dead psyllids containing a

155 developing parasitoid). We used in-vitro-cultivated pear trees (Williams cultivar) that were between

156 one and two years old, and between 0.75 and 1 meter in height. Plants were obtained from Battistini

157 Vivai (www.battisti-rebschule.it) and stored in individual cages in a climatic chamber at $24^{\circ} \mathrm{C}$.

158 After fourteen days, pear trees were checked daily for the presence of mummies and adult psyllids.

159 Each mummy was then isolated in a falcon tube with a drop of honeydew until the parasitoid

160 emerged. Development time was measured as the number of days from oviposition to adult

161 emergence. Host suitability (number of mummies divided by the number of ovipositor insertions)

162 was calculated for each host instar to determine the developmental instar that provides the best egg-

163 to-adult development. The emergence rate was also calculated as the number of emerging adult

164 parasitoid divided by the total number of mummies, for each treatment. Finally, the sex-ratio was

165 calculated as the number of males divided by the total number of emerging individuals. Three days

166 after emergence, parasitoids (males and females) were stored in a freezer at $-20^{\circ} \mathrm{C}$ for future

167 measurements of tibia size and egg load.

168 The size of the tibia was used as a proxy for individual body size. The left hind tibia of each

169 emerging individual was measured using the software ImageJ 1.440 (Rasband, W.S., US National

170 Institutes of Health, Bethesda, MD, USA). To estimate their egg load, each emerging female was

171 squeezed from the abdomen beneath a cover slip on a microscope slide (Manfield and milles, 2002):

172 the female was placed on an object blade with a small amount of water and crushed with a

173 coverslip. To better extract the eggs, the pressure exerted on the coverslip started from the head

174 towards the abdomen. Only ellipsoidal mature eggs (Figure 1) were counted. 


\section{Statistical analysis}

176 Generalized linear models (GLMs) were fitted to the data to test the potential influence of host

177 instar (explanatory variable, with five levels) on female parasitoids behaviors and emerging

178 parasitoid quality. Response variables were the number of host feeding events (Poisson

179 distribution), the time spent host feeding (Gaussian distribution), the time spent grooming

180 (Gaussian distribution), the time spent walking (Gaussian distribution), the time spent resting

181 (Gaussian distribution), the number of antennal contacts (Poisson distribution), the number of

182 ovipositor insertions (Poisson distribution), the host acceptance rate (Gaussian distribution), the

183 number of mummies (Poisson distribution), the host suitability (Gaussian distribution), the

184 emergence rate (Binomial distribution), and the egg load (Poisson distribution).

185 We also used a GLM (Gaussian distribution) to test the potential influence of the sex, of the host

186 instar, and of their interaction, on the tibia size and the development of emerging parasitoids. All

187 significant GLMs were followed by Tukey post hoc tests to compare each level of the same factor

188 (host instar and sex). In addition, Spearman correlation tests were performed between the tibia size

189 and the egg load at the emergence of each female, for each host instar. Finally, using $\chi^{2}$ tests, we

190 compared the experimental results of sex ratio obtained for each larval instar to a 50/50 theoretical

191 sex ratio.

192 Statistical analyses were performed using R version 3.3.3 Copyright (C) 2016 The R Foundation for

193 Statistical Computing for Mac. All tests were applied under two-tailed hypotheses, and the

194 significance level was set at 0.05 .

\section{Results}

\section{The influence of host development on parasitoid behavior}

198 The number of antennal contacts varied significantly with host developmental instar $(\chi 2=800.30$,

$199 \mathrm{DF}=4, \mathrm{P}<0.001)$. The minimum value was observed for $T$. insidious females exposed to second 
instar psyllids, while the maximum was observed for individuals exposed to third and fourth larval

201 instars (Table 1) (S1). Regarding the average number of ovipositor insertions, it was significantly

202 different between larval instars $(\chi 2=443.92, \mathrm{DF}=4, \mathrm{P}<0.01)$ : the second larval instar received a

203 significantly lower number of ovipositor insertions than the third, fourth and fifth larval instars

204 (Table 1) (S1). Host acceptance by parasitoids was significantly different between the different

205 developmental instars $(\mathrm{F}=5.01, \mathrm{D}=4, \mathrm{P}<0.01)$, with acceptance for fifth instars lower than for all

206 other developmental instars (Table 1) (S1).

207 Host instar significantly influenced the time spent by parasitoids walking $(\mathrm{F}=3.19, \mathrm{DF}=4$,

$208 \mathrm{P}<0.05)$. In the presence of fifth instar larvae, the parasitoid spent significantly more time walking,

209 than in the presence of second instar larvae (Table 1) (S1). Host developmental instar had a

210 significant impact on the time spent resting $(\mathrm{F}=5.50, \mathrm{DF}=4, \mathrm{P}<0.01)$. Parasitoids exposed to third,

211 fourth and fifth instar larvae spent less time resting than those exposed to second instar larvae

212 (Table 1) (S1).

213 The average number of host-feeding behaviors was very low; for each developmental instar

214 about 1 out of 200 larvae were killed and then eaten by a parasitoid for an average duration of

$2150.10 \%$ of the total experimental time. No significant differences between developmental instars

216 were observed for the occurrence $\left(\mathrm{X}^{2}=0.19, \mathrm{DF}=4, \mathrm{P}=0.10\right)$ or the duration of host feeding $(\mathrm{F}=0.72$,

$217 \mathrm{DF}=4, \mathrm{P}=0.58$ ) (Table 1) (S1). Grooming accounted for an important part of the behavior expressed

218 by the parasitoid over thirty minutes, and was expressed in a similar proportion in all developmental

219 instars tested (around 42\%) $(\mathrm{F}=0.90, \mathrm{DF}=4, \mathrm{P}=0.47)($ Table 1) $(\mathrm{S} 1)$.

\section{The influence of host development on parasitism and offspring quality}

221 The average number of mummies was significantly different between developmental instars

$222\left(\mathrm{X}^{2}=111.22, \mathrm{DF}=4, \mathrm{P}<0.001\right)$, with a higher mean number of mummies produced when parasitizing

223 third- and fourth instar psyllids than first- and second instar psyllids (Table 2) (S1). Host suitability

224 was significantly influenced by psyllid developmental instar $(\mathrm{F}=8.50, \mathrm{DF}=4, \mathrm{P}<0.001)$, with a lower

225 suitability of first instar hosts than third instars hosts. Fifth instars showed a null suitability as they 
226 produced no mummies (Table 2) (S1). The emergence rate did not vary significantly with host

227 developmental instar $\left(\chi^{2}=44.463, \mathrm{DF}=3, \mathrm{P}>0.05\right)$. Of the 162 mummies obtained, 155 resulted in

228 emergence. All mummies resulted in emergence when development occurred in the third instar

229 (72/72), whereas when development of parasitoids occurred in first and fourth instar larvea, two

230 mummies did not emerge (2/14 and 2/60, respectively) and for development in second instar larvae,

231 three mummies did not emerge (3/16).

232 Parasitoids emerging from the first, second, and third instar larvae had a balanced sex ratio

$233\left(\chi^{2}=0.5, \mathrm{P}>0.5, \chi^{2}=0.8, \mathrm{P}>0.4, \chi^{2}=1.48, \mathrm{P}>0.2\right.$, respectively $)$, whereas individuals emerging from the

234 fourth instar larvae had a sex ratio that was largely skewed in favor of females (37 females for 8

235 males) $\left(\chi^{2}=8.52, \mathrm{P}<0.01\right)$ (Table 2) (S1). Tibia lengths of parasitoids differed significantly between

236 the two sexes, males being smaller than females $(0.33 \mathrm{~mm}$ vs. $0.35 \mathrm{~mm}$, respectively), regardless of

237 the host developmental instar $(\mathrm{F}=43.35, \mathrm{DF}=1, \mathrm{P}<0.001)$ (Table 2) (S1). Tibia length also varied

238 with host developmental instar $(\mathrm{F}=3.33, \mathrm{DF}=3, \mathrm{P}<0.05)$. Male and female parasitoids from second

239 instar larvae were in average smaller than those developed from other developmental instars (Table

240 2) ( $\mathrm{S} 1)$. No interaction was detected between sex and developmental instar factors $(\mathrm{F}=0.96, \mathrm{DF}=3$,

$241 \mathrm{P}=0.41)$.

242 No impact of host instar was observed on female egg load, which showed an average of

$24310.94 \pm 9.00$ mature eggs over all experimental conditions $\left(\mathrm{X}^{2}=549.71, \mathrm{DF}=3, \mathrm{P}>0.2\right)($ Table 2$)$

244 (S1). However, a significant correlation between the tibia length and female egg load was observed

245 for females that developed in fourth instar hosts (Spearman's $\mathrm{R}=0.50, \mathrm{P}<0.001, \mathrm{n}=46$ ), but not for

246 females that emerged from the other developmental instars $(\mathrm{R}=0.38, \mathrm{P}>0.05, \mathrm{n}=9, \mathrm{R}=0.66, \mathrm{P}>$

$2470.05, \mathrm{n}=9$, and $\mathrm{R}=0.12, \mathrm{P}>0.05, \mathrm{n}=35$, for instar 1, 2, and 3, respectively) (Figure 2). The

248 developmental time of parasitoids was significantly different among host instars $(\mathrm{F}=36.11, \mathrm{DF}=3$,

$249 \mathrm{P}<0.001)$. Parasitoid eggs laid in first instar hosts took longer to emerge from the mummies than

250 parasitoid eggs laid in other developmental instars (Table 2) (S1). There was no significant 
251 difference in development time between sexes $(\mathrm{F}=0.14, \mathrm{DF}=1, \mathrm{P}=0.71)$, and no interaction occurred

252 between the two factors $(\mathrm{F}=1.52, \mathrm{DF}=3, \mathrm{P}=0.21)($ Table 2) $(\mathrm{S} 1)$.

\section{Discussion}

255 According to Armand et al. (1991, 1990), and Booth (1992), T. insidiosus tends to oviposit in the

256 fourth and fifth larval instars of the pear psyllid C. pyri, whereas McMullen (1966) suggest that this

257 parasitoid oviposits mainly in the first three larval instars. In our study, we observed that this

258 parasitoid accepted all host instars for oviposition. However, they had a lower acceptance rate for

259 fifth instar hosts, in which no parasitoid could develop, and higher mummy production was found

260 when eggs were laid in third and fourth instar larvae. Parasitoids spent more time resting and less

261 time exploring the patch when exposed to the first two larval instars, and first instar hosts presented

262 the lowest suitability for T. insidiosus of the instars in which mummy development was possible.

263 Second instar hosts received few antennal contacts and as few ovipositor insertions as fifth instar

264 hosts. First and second instar larvae together accounted for only $20 \%$ of the total number of

265 mummies produced in this experiment. In general, low parasitism rates of young host instars are

266 associated with higher mortality of the host larvae, which are more susceptible to oviposition

267 injuries from stinging and/or venom (Colinet et al., 2005). In addition, the mortality rate of young

268 parasitized instars could be high because hosts are more likely to die between successive molts. All

269 parameters taken together, we suggest that third and fourth instar psyllid larvae are the most suitable

270 hosts for the development of $T$. insidiosus, both qualitatively and quantitatively.

$271 \quad$ We found that Trechnites insidiosus was more motivated to forage for hosts in presence of

272 third, fourth and fifth instar larvae, with more time spent moving and less time spent resting than

273 when exposed to the first and second instar larvae. Clues left by older psyllid larvae (e.g. honeydew,

274 exuviae and chemical volatiles) could stimulate the locomotor activity of the parasitoid and thus

275 increase its probability of finding hosts. This phenomenon was previously observed in the encytrid

276 parasitoid Psyllaephagus pistaciae whose searching time, locomotion, antennal drumming, and 
277 ovipositor probing behaviors were increased by the presence of pistachio psylla honeydew

278 (Mehrnejad and Copland, 2006). The antochorid predator Orius sauteri tends to forage more and to

279 lay more eggs in the presence of the pear psylla Cacopsylla chinensis honeydew (Ge et al., 2019).

280 Our results suggest that the amount and/or the quality of the clues present in the environment may

281 be important stimulating cues for the parasitoid. Determining the nature of these clues influencing

282 the exploratory behavior of $T$. insidiosus could be an additional step to unravel the factors driving

283 the interactions between psyllids and parasitoids.

284 We found that third and fourth instar psyllids represent the most suitable hosts for 285 oviposition, as $80 \%$ of the mummies obtained in this experiment resulted from these two 286 developmental instars. Although they are larger and therefore more difficult to handle by the 287 parasitoid than first and second instar hosts, they appear to be the most suitable candidates for the 288 female parasitoid, given the trade-off between the nutritional quality of the host and its behavioral 289 and immune defense capabilities. From a biological control perspective, by parasitizing the fourth 290 instars of $C$. pyri, $T$. insidiosus will mainly parasitized psyllid individuals that have escape to all 291 other mortality factors at the end of their developmental cycle and just before the reproduction of 292 the pest occurs. Such a feature gives the parasitoid a potentially important control efficiency on the 293 population dynamics of its host with an immediate impact on the resulting imaginal population, and 294 thus on the next generation of psyllids (Armand et al., 1991).

295 Our results showed a lower attraction and acceptance of $T$. insidiosus to fifth instar psyllids, 296 as few antennal contacts and ovipositors insertion were performed, and no mummies were 297 produced. Fifth instar larvae are probably too large and too advanced in ontogeny to allow proper 298 development of $T$. insidiosus. Indeed, advanced larval instars of psyllids are able to escape the 299 parasitoid more easily than the earlier developmental instars (Villagra et al., 2002). Such differences 300 in escape behavior between host instars are commonly reported in aphid-parasitoid interactions, in 301 which more mature hosts also generally have a higher capacity to encapsulate parasitoid eggs 302 (Colinet et al., 2005). For example, it has also been shown that the last instar of the aphid Toxoptera 
citricida exhibits a greater immune response to parasitism than younger instars (Walker and Hoy,

304 2003). The absence of mummies for the fifth instar of psyllids could therefore be explained by a

305 combination of behavioral and immune responses of the psyllid to parasitoid attack (Colinet et al.,

306 2005). Fifth instar larvae of $C$. pyri are therefore completely unsuitable for parasitoid development.

307 Grooming accounts for nearly half of the activity of $T$. insidiosus, regardless of the host

308 instar encountered. Psyllids, especially larvae, produce large amounts of honeydew (Civolani,

309 2012), which is highly concentrated in sugar (Le Goff et al., 2019). After an ovipositor insertion,

310 residues of honeydew left on the cuticule probably promote bacterial and/or fungal infections on the

311 parasitoid's body. Selection likely favored individuals that spent a lot of time cleaning themselves

312 (legs, ovipositor, antennae), because this behavior may not only help parasitoids to live longer, but

313 also contributes maintain high levels of locomotor activity and host detection ability (Zhukovskaya

314 et al., 2013). For psyllids, high honeydew production could also be a protection against parasitoids.

315 Indeed, it has been observed that the honeydew of the pear psylla Cacopsylla chinensis limits the

316 foraging behavior of its predators and could provide a physical defense for the psyllid (Ge et al.,

317 2019). Moreover, T. insidiosus has been observed attempting to oviposit in in honeydew droplets,

318 allowing time for psyllid larvae to escape. When attacking aphids, parasitoids also waste time

319 manipulating and inserting their ovipositors into aphid exuviae (Muratori et al., 2008). Finally, the

320 time T. insidiosus spends grooming itself is time that is not spent searching for a host. An

321 experiment to analyze the behavior of the parasitoid when faced with exuviae of different instars

322 and/or honeydew could be conducted to clarify the role that psyllid waste might play in its defense

323 against parasitoids, in terms of the parasitoid's time budget.

324 Regarding the parasitoid fitness indicators obtained in our experiments, parasitoids

325 distribute their offspring in a balanced sex ratio in the first three host instars, while fourth instar

326 psyllids were chosen by the parasitoid to lay a majority of females. It has already been shown that

327 host size/instar can influence the sex ratio of parasitoid offspring: eggs leading to the emergence of

328 females tend to be laid in large hosts (Bernal et al., 1997; Jervis and Kidd, 1986; Van Den Assem et 
al., 1982). This strategy is consistent with the host size distribution model, which assumes that the amount of resources available for parasitoid development determines its fitness (Charnov, 1976; Charnov and Skinner, 1985). Thus, it is more profitable for a female parasitoid to lay female eggs in large hosts that provide more resources (Jervis and Kidd, 1986), so they ultimately have a higher egg load. Our experiments were conducted with solitary females, but it would be interesting to test whether this species produces more males under conditions of competition for large hosts, as predicted by the theory of local mate competition (Hamilton, 1967). instars, probably because these developmental instars exhibit more abundant reserves that allow for better growth of the parasitoid. More surprisingly, females that were laid in first instar hosts appeared to be as large as those that developed in third and fourth instar hosts. One mechanism that would explain these observations is that when an egg is laid in a first instar host, the egg does not begin to develop until the psyllid larva reaches a more advanced development instar (Colinet et al.,

342 2005). This hypothesis is supported by the fact that individuals from a first instar host take longer to 343 develop than individuals from other instars. It is also possible that parasitoid larvae develop less 344 rapidly in such a host in order to keep it alive longer, thus ensuring completion of their 345 development. These hypotheses could be confirmed by dissecting second, third and fourth instar larvae that were parasitized during the first development instar, and identifying the developmental

347 instar of the parasitoid.

We observed a fairly low egg load in $T$. insidiosus females regardless of the host instar in which they developed, suggesting that this species is synovogenic and produces eggs throughout its

350 life (approximately 20 days when fed under laboratory conditions (Berthe, 2018)). Furthermore, it is 351 generally observed in parasitoids that the larger the female, the greater the egg load (Jia and Liu, 352 2018). In our study, this relationship was only observed for individuals from four instar hosts, 353 confirming that this larval instar is the most suitable for parasitoid development. Yet, some large 354 females did have no or few mature eggs. Yet, some large females had no or few mature eggs. It is 


\section{5}

possible that a stimulus such as psyllids honeydew, host feeding, or simply the presence of the host, is necessary to stimulate egg production (Aung et al., 2012; Pan et al., 2017).

Finally, although host feeding behavior was not affected by the host developmental instar, they may play an important role in the ecology of $T$. insidiosus and its interaction with the host. Host feeding is the consumption of host fluids exuding from oviposition wounds by the adult female parasitoid (Heimpel and Collier, 1996). This behavior has already been described in other encyrtidae species (Aung et al., 2012) but never in T. insidiosus. The number of host-feeding events that were observed in our experiments was very low, likely because the females we used were fed, hydrated and full of eggs. Therefore, their only optimal foraging strategy under these conditions was probably to lay as many eggs as possible. To better understand under what conditions hostfeeding behavior is expressed, further experiments should be conducted on fertilized females with poor access to food, and/or with low egg loads. Such an experiment would highlight the trade-off between feeding to replenish their energetic reserves/egg load, and to lay eggs, when a femane meet a psyllid larvae. It is also possible that $T$. insidiosus is able to discriminate between a parasitized and a non-parasitized host, as is the case with most parasitoid species (van Alphen and Visser, 1990). Thus, a female arriving in a patch already visited by a conspecific would be more prone to express host-feeding behavior on a host parasitized by a competitor, and thus decrease the competition pressure encountered by its offspring. However, this hypothesis has yet to be tested.

The purpose of this study was to determine key elements in the interaction between pear psyllid C. pyri and the specialist parasitoid T. insidiosus, including the most profitable host instars for its development. We showed that third and fourth instar larvae are the most suitable hosts, both behaviorally and physiologically, for the parasitoid to produce high quantity and quality offspring. These results provide a basis for further studies on psyllid-parasitoid interactions, and are a first step to fill the data gap on the insect $T$. insidiosus in the literature, especially regarding its general biology and behavior, and open perspectives on the use of this parasitoid species in integrated pest management strategies against pear psyllids. 


\section{Acknowledgments}

382 This research was supported by the grant 12/1/7798 of the PPP call of the Walloon Region, by an

383 additional grant from Viridaxis S.A. and by the Interreg-Proverbio project funded by SPW-Feder-

384 Interreg (https://www.interreg-fwvl.eu). KT and FR were supported by the F.R.S.-FNRS. This

385 publication is number BRC361 of the Biodiversity Research Centre.

\section{Author contribution}

388 GJLG, JB, TH designed the study, JB made the experiments, GJLG and JB analyzed the data. BD,

389 OL, GJLG caught the insect to start the rearing, maintained the rearing and the plant cultures.

390 GJLG, KT, FR and TH wrote the manuscript. All authors contributed to manuscript improvement

391 and gave their final approval for publication.

\section{Conflict of interest statement}

393 The authors of this article do not present any conflict of interest

\section{Data availability statement}

396 The datasets analyzed for the current study are available at the following DOI:

397 https://doi.org/10.6084/m9.figshare.13187642.v1 


\section{References}

Albittar, L., Ismail, M., Bragard, C. \& Hance, T. (2016) Host plants and aphid hosts influence the selection behaviour of three aphid parasitoids (Hymenoptera: Braconidae: Aphidiinae). European Journal of Entomology,, 8.

Armand, E., Lyoussouf, A. \& Rieux, R. (1991) Evolution du complexe parasitaire des psylles du poirier Psylla pyri et Psylla pyrisuga (Homoptera $\square$ : Psyllidae). Entomophaga, 36, 287-294.

Armand, E., Lyoussoufi, A., Arcier, F.F. d' \& Rieux, R. (1990) Inter-relations entre les populations du psylle du poirier Psylla pyri (L.) (Hom., Psyllidae) et le complexe de ses parasitoïdes dans un verger traité du sud-est de la France. Journal of Applied Entomology, 110, 242-252.

Augustin, J., Boivin, G., Brodeur, J. \& Bourgeois, G. (2020) Effect of temperature on the walking behaviour of an egg parasitoid: disentangling kinetic response from integrated response. Ecological Entomology, 45, 741-750.

Aung, K.S.D., Takasu, K., Ueno, T. \& Takagi, M. (2012) Effect of Host-feeding on Reproduction in Ooencyrtus nezarae (Ishii) (Hymenoptera: Encyrtidae), an Egg Parasitoid of the Bean Bug Riptortus clavatus. Journal of the Faculty of Agriculture, Kyushu University, 57, 115-120. Avilla, J. \& Artigues, M. (1992) Parasitoides de Cacopsylla pyri (L.) (= Psylla pyri (L.)) presentes en una plantación comercial de peral en Lleida no sometida a tratamientos insecticidas. Bol. San. Veg. Plagas, 18, 133-138.

Bernal, J.S., Waggoner, M. \& Gonzalez, D. (1997) Reproduction of Aphelinus albidopus (Hymenoptera: Aphelinidae) on russian wheat aphid (Hemiptera: Aphididae) hosts. European Journal of Entomology, 94, 83-96.

Berthe, J. (2018) Evaluation de la capacité de parasitisme de Trechnites insidiosus pour le contrôle biologique du psylle du poirier Cacopsylla pyri (Master Thesis).

Booth, S.R. (1992) The potential of endemic natural enemies to suppress pear psylla, Cacopsylla pyricola Förster, in the Hood River Valley, Oregon.

Buès, R., Boudinhon, L. \& Toubon, J.-F. (2003) Resistance of pear psylla (Cacopsylla pyri L.; Hom., Psyllidae) to deltamethrin and synergism with piperonyl butoxide. Journal of Applied Entomology, 127, 305-312.

Bufaur, M., Harizanova, V. \& Stoeva, A. (2010) Parasitoids of the pear sucker Cacopsylla pyri L. (Psyllidae) in Bulgaria - Morphology and biology. Presented at the Jubilee Scientific Conference with International Participation Traditions and Challenges of Agricultiral Education, Science and business, Agricultural Universitty - Plovdiv.

Burts, E.C. (1983) Effectiveness of a Soft-Pesticide Program on Pear Pests. Journal of Economic Entomology, 76, 936-941.

Chang, J. (1977) Studies on the susceptibility of pear trees to pear psylla, Psylla pyricolla Foerster (Homoptera: psylllidae). 
434 Charnov, E.L. (1976) Optimal foraging, the marginal value theorem. Theoretical population

435 biology, 9, 129-136.

436 Charnov, E.L. \& Skinner, S.W. (1985) Complementary Approaches to the Understanding of

437 Parasitoid Oviposition Decisions. Environmental Entomology, 14, 383-391.

438 Civolani, S. (2012) The Past and Present of Pear Protection Against the Pear Psylla, Cacopsylla

439 pyri L. In Insecticides - Pest Engineering (ed. by Perveen, F.). InTech, pp. 385-408.

440 Civolani, S., Peretto, R., Caroli, L., Pasqualini, E., Chicca, M. \& Leis, M. (2007) Preliminary

441 Resistance Screening on Abamectin in Pear Psylla (Hemiptera: Psyllidae) in Northern Italy. Journal

442 of Economic Entomology, 100, 1637-1641.

443 Colinet, H., Salin, C., Boivin, G. \& Hance, Th. (2005) Host age and fitness-related traits in a

444 koinobiont aphid parasitoid. Ecological Entomology, 30, 473-479.

445 Dupont, S.T. \& Strohm, C.J. (2020) Integrated pest management programmes increase natural

446 enemies of pear psylla in Central Washington pear orchards. Journal of Applied Entomology, 144,

447 109-122.

448 Emami, M.S., Shishehbor, P. \& Karimzadeh, J. (2014) The influences of plant resistance on

449 predation rate of Anthocoris nemoralis (Fabricius) on Cacopsylla pyricola (Förster). Archives of

450 Phytopathology and Plant Protection, 47, 2043-2050.

451 Erler, F. (2004) Natural enemies of the pear psylla Cacopsylla pyri in treated vs untreated pear

452 orchards in Antalya, Turkey. Phytoparasitica, 32, 295-304.

453 FAOSTAT [WWW Document]. (2020). URL http://www.fao.org/faostat/en/\#data/QC [accessed on 454 2020].

455 Ge, Y., Liu, P., Zhang, L., Snyder, W.E., Smith, O.M. \& Shi, W. (2020) A sticky situation:

456 honeydew of the pear psylla disrupts feeding by its predator Orius sauteri. Pest Management

457 Science, 76, 75-84.

458 Guerrieri, E. \& Noyes, J.S. (2009) A review of the European species of the genus Trechnites

459 Thomson (Hymenoptera: Chalcidoidea: Encyrtidae), parasitoids of plant lice (Hemiptera:

460 Psylloidea) with description of a new species. Systematic Entomology, 34, 252-259.

461 Hamilton, W.D. (1967) Extraordinary sex ratios. A sex-ratio theory for sex linkage and inbreeding

462 has new implications in cytogenetics and entomology. Science (New York, N.Y.), 156, 477-488.

463 Heimpel, G.E. \& Collier, T.R. (1996) The evolution of host-feeding behaviour in insect parasitoids.

464 Biol. Rev., 71, 373-400.

465 Herard, F. (1985) Analysis of parasite and predator populations observed in pear orchards infested

466 by Psylla pyri (L.) (Hom. $\square$ : Psyllidae) in France. Agronomie, 5, 773-778.

467 Jaworska, K., Olszak, R.W. \& Zajac, R.Z. (1996) Parasitization rate on the larvae of pear

468 (Cacopsylla pyri) in orchards with differing intensity of chemical control. Acta Horticulturae, 422,

469 334-335.

470 Jerinic-Prodanovic, D., Protic, L. \& Mihajlovic, L. (2010) Predators and parasitoids of Cacopsylla 471 pyri (L.) (Hemiptera: Psyllidae) in Serbia. Pesticidi i fitomedicina, 25, 29-42. 
472 Jervis, M.A. \& Kidd, N.A.C. (1986) Host-feeding strategies in Hymenopteran parasitoids. Biol.

473 Rev., 61, 395-434.

474 Jia, Y.-J. \& Liu, T.-X. (2018) Dynamic host-feeding and oviposition behavior of an aphid parasitoid

475 Aphelinus asychis. BioControl, 63, 533-542.

476 Lacey, L., Arthurs, S., Horton, D. \& Miliczky, G. (2005) Spinosad and granulovirus effects on

477 codling moth. USDA-ARS, Yakima Agricultural Research Laboratory, Wapato, WA, Wapato.

478 Le Goff, G.J., Lebbe, O., Lohaus, G., Richels, A., Jacquet, N., Byttebier, V., et al. (2019) What are

479 the nutritional needs of the pear psylla Cacopsylla pyri? Arthropod-Plant Interactions, 13, 431-439.

480 Mansfield, S. \& Mills, N.J. (2002) Host Egg Characteristics, Physiological Host Range, and

481 Parasitism Following Inundative Releases of Trichogramma platneri (Hymenoptera:

482 Trichogrammatidae) in Walnut Orchards. Environmental Entomology, 31, 723-731.

483 McMullen, R.D. (1966) New Records of Chalcidoid Parasites and Hyperparasites of Psylla pyricola

484 Förster in British Columbia. The Canadian Entomologist, 98, 236-239.

485 Mehrnejad, M.R. \& Copland, M.J.W. (2006) Behavioral responses of the parasitoid Psyllaephagus

486 pistaciae (Hymenoptera: Encyrtidae) to host plant volatiles and honeydew. Entomological Science,

487 9, 31-37.

488 Miliczky, E.R. \& Horton, D.R. (2005) Densities of beneficial arthropods within pear and apple

489 orchards affected by distance from adjacent native habitat and association of natural enemies with

490 extra-orchard host plants. Biological Control, 33, 249-259.

491 Muratori, F.B., Damiens, D., Hance, T. \& Boivin, G. (2008) Bad housekeeping: why do aphids

492 leave their exuviae inside the colony? BMC Evolutionary Biology, 8.

493 Oudeh, B., Kassis, W. \& Abu-Tara, R. (2013) Seasonal Activity of the Predator, Anthocoris

494 nemoralis (F.) and the Parasitoid, Trechnites psyllae (R.) against the Pear Psylla Cacopsylla

495 pyricola (F.) (Hemiptera: Psyllidae). Egyptian Journal of Biological Control, 23, 17-23.

496 Pan, M.-Z., Wang, L., Zhang, C.-Y., Zhang, L.-X. \& Liu, T.-X. (2017) The influence of feeding and

497 host deprivation on egg load and reproduction of an aphid parasitoid, Aphidius gifuensis

498 (Hymenoptera: Braconidae). Applied Entomology and Zoology, 52, 255-263.

499 Retan, A. \& Peterson, V. (1982) Pear Psylla. Insect answers.

500 Sanchez, J.A. \& Ortin-Angulo, M.C. (2012) Abundance and population dynamics of Cacopsylla

501 pyri (Hemiptera: Psyllidae) and its potential natural enemies in pear orchards in southern Spain.

502 Crop Protection, 32, 24-29.

503 Seemüller, E. \& Schneider, B. (2004) 'Candidatus Phytoplasma mali', 'Candidatus Phytoplasma

504 pyri' and 'Candidatus Phytoplasma prunorum', the causal agents of apple proliferation, pear decline

505 and European stone fruit yellows, respectively. International Journal of Systematic and

506 Evolutionary Microbiology, 54, 1217-1226.

507 Sigsgaard, L., Esbjerg, P. \& Philipsen, H. (2006a) Controlling pear psyllids by mass releasing

508 Anthocoris nemoralis and A. nemorum (Heteroptera: Anthocoridae). Journal of Fruit and

509 Ornamental Plant Research, 14, 10. 
510 Sigsgaard, L., Esbjerg, P. \& Philipsen, H. (2006b) Experimental releases of Anthocoris nemoralis F. 511 and Anthocoris nemorum (L.) (Heteroptera: Anthocoridae) against the pear psyllid Cacopsylla pyri 512 L. (Homoptera: Psyllidae) in pear. Biological Control, 39, 87-95.

514 Tougeron, K., Ilitis, C., Renoz, F., Albitar, L., Hance, T., Demeter, S., Le Goff, G.J. Ecology and 515 biology of the parasitoid Trechnites insidiosus and its potential for biological control of pear 516 psyllids. Pest management science.

517 Unruh, T.R., Westigard, P.H. \& Hagen, K.S. (1994) Pear Psylla. In Biological control in the

518 Western United State. DANR Publications, pp. 95-100.

519 Van Alphen, J.J.M. \& Visser, M.E. (1990) Superparasitism as an Adaptive Strategy for Insect

520 Parasitoids. Annual Review of Entomology, 35, 59-79.

521 Van Den Assem, J., Gijswijt, M.J. \& Nübel, B.K. (1982) Characteristics of courtship and mating

522 behaviour used as classificatory criteria in Eulophidae-Tetrastichinae (Hymenoptera), with special

523 reference to the genus Tetrastichus. Tijdscrift voor entomologie, 125, 205-219.

524 Villagra, C.A., Ramirez, C.C. \& Niemeyer, H.M. (2002) Antipredator responses of aphids to

525 parasitoids change as a function of aphid physiological state. Animal behaviour, 64, 677-683.

526 Walker, A.M. \& Hoy, M.A. (2003) Responses of Lipolexis oregmae (Hymenoptera: Aphidiidae) to

527 Different Instars of Toxoptera citricida (Homoptera: Aphididae). Journal of Economic Entomology,

528 96, 1685-1692.

529 Zhukovskaya, M., Yanagawa, A. \& Forschler, B.T. (2013) Grooming Behavior as a Mechanism of

530 Insect Disease Defense. Insects, 4, 609-630. 
Figure 1 : mature eggs of Trechnites insidiosus

Figure 2: Correlation between the number of eggs per female from each developmental stage with tibia size

Table 1: Mean total number and mean total duration \pm standard deviation of the different observed behaviours, and number of replicates for each psyllid larval host stage. Different letters indicate significant differences to Tukey HSD tests

Table 2: Mean \pm standard deviation of the different measured parameters of emerging parasitoids quality, and number of replicates for each psyllid larval host stage. Different letters indicate significant differences according to Tukey HSD tests 
100 แก

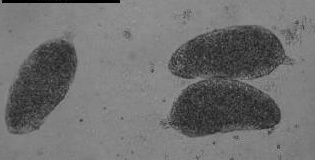




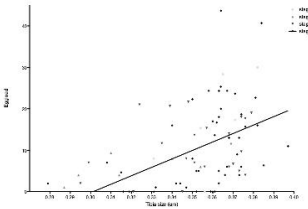


Table 1: Mean total number and mean total duration \pm standard deviation of the different observed behaviours, and number of replicates for each psyllid larval host stage. Different letters indicate significant differences to Tukey HSD tests

\begin{tabular}{|c|c|c|c|c|c|}
\hline & Instar 1 & Instar 2 & Instar 3 & Instar 4 & Instar 5 \\
\hline $\begin{array}{l}\text { Number of antennal } \\
\text { contacts }\end{array}$ & $\begin{array}{l}17.50 \pm \\
21.06 \mathrm{a} \\
(\mathrm{n}=10)\end{array}$ & $\begin{array}{c}9.60 \pm 13.66 \\
b(n=10)\end{array}$ & $\begin{array}{c}32.10 \pm 30.19 \\
\text { c }(n=10)\end{array}$ & $\begin{array}{l}31.70 \pm \\
16.26 \mathrm{c} \\
(\mathrm{n}=10)\end{array}$ & $\begin{array}{c}16.00 \pm 10.19 \\
a(n=10)\end{array}$ \\
\hline $\begin{array}{l}\text { Number of ovipositor } \\
\text { insertions }\end{array}$ & $\begin{array}{l}10.00 \pm \\
13.33 \mathrm{a} \\
(\mathrm{n}=10)\end{array}$ & $\begin{array}{c}4.70 \pm 7.90 b \\
(n=10)\end{array}$ & $\begin{array}{c}14.80 \pm 11.72 \\
\mathrm{c}(\mathrm{n}=10)\end{array}$ & $\begin{array}{c}17.80 \pm 11.31 \\
\mathrm{c}(\mathrm{n}=10)\end{array}$ & $\begin{array}{c}4.00 \pm 3.62 b \\
(n=10)\end{array}$ \\
\hline Host acceptance & $\begin{array}{c}0.56 \pm 0.27 \mathrm{a} \\
(\mathrm{n}=6)\end{array}$ & $\begin{array}{c}0.54 \pm 0.31 \mathrm{a} \\
(\mathrm{n}=5)\end{array}$ & $\begin{array}{c}0.50 \pm 0.17 \mathrm{a} \\
(\mathrm{n}=9)\end{array}$ & $\begin{array}{c}0.55 \pm 0.15 a \\
(n=10)\end{array}$ & $\begin{array}{c}0.22 \pm 0.11 b \\
(n=10)\end{array}$ \\
\hline Time walking (\%) & $\begin{array}{c}28.27 \pm \\
21.72 \mathrm{ab} \\
(\mathrm{n}=10)\end{array}$ & $\begin{array}{c}18.49 \pm 16.34 \\
a(n=10)\end{array}$ & $\begin{array}{c}36.06 \pm 18.77 \\
a b(n=10)\end{array}$ & $\begin{array}{c}33.32 \pm 6.91 \\
\mathrm{ab}(\mathrm{n}=10)\end{array}$ & $\begin{array}{c}42.26 \pm 10.73 \\
b(n=10)\end{array}$ \\
\hline Time resting (\%) & $\begin{array}{c}16.73 \pm \\
25.22 \mathrm{ab} \\
(\mathrm{n}=10)\end{array}$ & $\begin{array}{c}32.14 \pm 31.67 \\
a(n=10)\end{array}$ & $\begin{array}{c}3.76 \pm 6.14 b \\
(n=10)\end{array}$ & $\begin{array}{c}0.86 \pm 1.53 b \\
(n=10)\end{array}$ & $\begin{array}{c}0.71 \pm 1.84 b \\
(\mathrm{n}=10)\end{array}$ \\
\hline $\begin{array}{l}\text { Number of host } \\
\text { feeding events }\end{array}$ & $\begin{array}{c}0.00 \pm 0.00 a \\
(n=10)\end{array}$ & $\begin{array}{c}0.10 \pm 0.32 a \\
(n=10)\end{array}$ & $\begin{array}{c}0.10 \pm 0.32 \mathrm{a} \\
(\mathrm{n}=10)\end{array}$ & $\begin{array}{c}0.10 \pm 0.32 \mathrm{a} \\
(\mathrm{n}=10)\end{array}$ & $\begin{array}{c}0.00 \pm 0.00 \mathrm{a} \\
(\mathrm{n}=10)\end{array}$ \\
\hline $\begin{array}{l}\text { Host feeding duration } \\
(\%)\end{array}$ & $\begin{array}{c}0.00 \pm 0.00 \mathrm{a} \\
(\mathrm{n}=10)\end{array}$ & $\begin{array}{c}0.20 \pm 0.62 a \\
(n=10)\end{array}$ & $\begin{array}{c}0.01 \pm 0.04 \mathrm{a} \\
(\mathrm{n}=10)\end{array}$ & $\begin{array}{c}0.22 \pm 0.70 a \\
(n=10)\end{array}$ & $\begin{array}{c}0.00 \pm 0.00 \mathrm{a} \\
(\mathrm{n}=10)\end{array}$ \\
\hline $\begin{array}{l}\text { Grooming duration } \\
(\%)\end{array}$ & $\begin{array}{l}36.16 \pm \\
19.97 \mathrm{a} \\
(\mathrm{n}=10)\end{array}$ & $\begin{array}{c}40.19 \pm 16.67 \\
a(n=10)\end{array}$ & $\begin{array}{c}40.15 \pm 21.65 \\
a(n=10)\end{array}$ & $\begin{array}{c}41.81 \pm 11.04 \\
\mathrm{a}(\mathrm{n}=10)\end{array}$ & $\begin{array}{c}49.74 \pm 11.01 \\
a(n=10)\end{array}$ \\
\hline
\end{tabular}


Table 2: Mean \pm standard deviation of the different measured parameters of emerging parasitoids quality, and number of replicates for each psyllid larval host stage. Different letters indicate significant differences according to Tukey HSD tests

\begin{tabular}{|c|c|c|c|c|c|}
\hline & Instar 1 & Instar 2 & Instar 3 & Instar 4 & Instar 5 \\
\hline $\begin{array}{l}\text { Number of } \\
\text { mummies }\end{array}$ & $\begin{array}{c}1.33 \pm 1.73 \mathrm{a} \\
(\mathrm{n}=10)\end{array}$ & $\begin{array}{c}1.44 \pm 2.65 \\
a(n=10)\end{array}$ & $\begin{array}{c}6.55 \pm 4.61 \\
b(n=10)\end{array}$ & $\begin{array}{c}5.78 \pm 3.67 b \\
(n=10)\end{array}$ & $\begin{array}{c}0.00 \pm 0.00 \mathrm{c} \\
(\mathrm{n}=10)\end{array}$ \\
\hline Host suitability & $\begin{array}{c}0.15 \pm 0.18 \mathrm{ac} \\
(\mathrm{n}=6)\end{array}$ & $\begin{array}{c}0.52 \pm 0.28 \\
a b(n=5)\end{array}$ & $\begin{array}{c}0.60 \pm 0.36 \\
b(n=10)\end{array}$ & $\begin{array}{c}0.40 \pm 0.24 \\
a b(n=10)\end{array}$ & $\begin{array}{c}0.00 \pm 0.00 c \\
(n=9)\end{array}$ \\
\hline Sex ratio & 0.33 & 0.30 & 0.49 & 0.21 & \\
\hline $\begin{array}{l}\text { Female tibia size } \\
(\mathrm{mm})\end{array}$ & $\begin{array}{c}0.36 \pm 0.02 \mathrm{a} \\
(\mathrm{n}=9)\end{array}$ & $\begin{array}{c}0.33 \pm 0.03 \\
b(n=9)\end{array}$ & $\begin{array}{c}0.36 \pm 0.02 \\
a(n=35)\end{array}$ & $\begin{array}{c}0.36 \pm 0.02 \mathrm{a} \\
(\mathrm{n}=46)\end{array}$ & \\
\hline $\begin{array}{lll}\text { Male } & \text { tibia } & \text { size } \\
(\mathrm{mm}) & & \\
\end{array}$ & $\begin{array}{c}0.33 \pm 0.02 a \\
(n=3)\end{array}$ & $\begin{array}{c}0.32 \pm 0.02 \\
b(n=4)\end{array}$ & $\begin{array}{c}0.33 \pm 0.03 \\
b(n=36)\end{array}$ & $\begin{array}{c}0.34 \pm 0.02 b \\
(n=12)\end{array}$ & \\
\hline Egg load & $\begin{array}{c}19.77 \pm 10.50 \\
a(n=9)\end{array}$ & $\begin{array}{c}8.48 \pm 6.75 \\
a(n=9)\end{array}$ & $\begin{array}{l}11.44 \pm \\
7.45 \mathrm{a} \\
(\mathrm{n}=35)\end{array}$ & $\begin{array}{c}11.30 \pm 10.70 \\
a(n=46)\end{array}$ & \\
\hline $\begin{array}{l}\text { Developmental } \\
\text { time of females } \\
\text { (days) }\end{array}$ & $\begin{array}{c}30.33 \pm 2.65 \\
a(n=9)\end{array}$ & $\begin{array}{c}22.33 \pm 3.74 \\
b(n=9)\end{array}$ & $\begin{array}{l}22.66 \pm \\
2.83 \mathrm{bc} \\
(\mathrm{n}=35)\end{array}$ & $\begin{array}{c}21.89 \pm 2.08 \\
c(n=46)\end{array}$ & \\
\hline \begin{tabular}{l}
\multicolumn{2}{l}{$\begin{array}{l}\text { Developmental } \\
\text { time of males } \\
\text { (days) }\end{array}$} \\
\end{tabular} & $\begin{array}{c}31.33 \pm 1.53 \mathrm{a} \\
(\mathrm{n}=3)\end{array}$ & $\begin{array}{c}26.25 \pm 7.23 \\
b(n=4)\end{array}$ & $\begin{array}{l}22.86 \pm \\
2.83 \mathrm{bc} \\
(\mathrm{n}=36)\end{array}$ & $\begin{array}{c}20.50 \pm 1.93 \\
c(n=12)\end{array}$ & \\
\hline
\end{tabular}

